\title{
Research Paper \\ Investigating the mediating role of mindfulness in the relationship between autonomy supportive environmental and critical thinking in students
}

\begin{abstract}
Citation: Chalmeh R, Fouladchang M, Jowkar B, Fazilat-Pour M. Investigating the mediating role of mindfulness in the relationship between autonomy supportive environmental and critical thinking in students. J of Psychological Science. 2022; 20(107): 1965-1978.
\end{abstract}

Reza Chalmeh', Mahbubeh Fouladchang ${ }^{2}$, Bahram Jowkar ${ }^{3}$, Masoud Fazilat-Pour ${ }^{2}$

1. Ph.D Student, Educational Psychology Department, Education and Psychology Faculty, Shiraz University, Shiraz, Iran. 2. Associate Professor, Educational Psychology Department, Education and Psychology Faculty, Shiraz University, Shiraz, Iran.

3. Professor, Educational Psychology Department, Education and Psychology Faculty, Shiraz University, Shiraz, Iran.

URL: https://psychologicalscience.ir/article-1-1045-fa.html
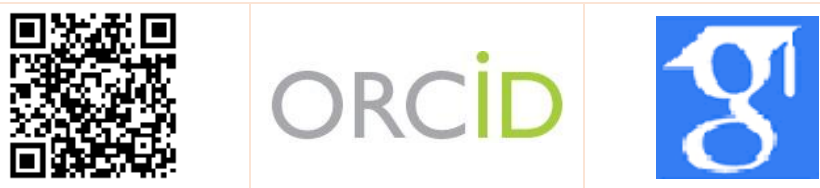

\section{A R T I C L E I N F O A B S T R A C T}

Keywords:

critical thinking,

mindfulness,

autonomy supportive

environmental,

students

Received: 24 Nov 2020

Accepted: 04 Jan 2021

Available: 21 Jan 2022
Background: Critical thinking has been one of the most important concepts in recent years; But the identification of predictor variables in the form of a structural model and in the educational environment has not been studied.

Aims: The purpose of this study was to investigate the role of mindfulness as a mediator in the relationship between autonomy supportive environment and critical thinking.

Methods: The research method is correlation and modeling of structural equations. The population of this study included all high school students in Shiraz city in the academic year 2019-2020. 525 students (301 girls and 224 boys) were selected by multi-stage cluster random sampling. Participants answered three questionnaires: autonomy supportive environmental scale (Assor and et al, 2002, Assor, 2012), Freiburg mindfulness questionnair (short form, Walach and et al, 2006), and California critical thinking test (Facione, 2013). Data were analyzed using structural equation modeling and AMOS software and fitness indicators.

Results: The results showed that the proposed model has a good fit with data. Direct path coefficients indicated that the autonomy supportive environment was a significant predictor of mindfulness ( $\mathrm{P}$ $<0.001, \beta=0.18)$ and critical thinking $(\mathrm{P}<0.001, \beta=0.18)$. Mindfulness was also a significant predictor of critical thinking $(\mathrm{P}<0.001, \beta=0.28)$. In addition, the results indicated that mindfulness was able to play a mediating role in the relationship between autonomy supportive environment and critical thinking.

Conclusion: Environmental characteristics such as autonomy supportive environmental along with interpersonal factors such as mindfulness play an important role in students' critical thinking and it is necessary to pay attention to them in educational planning.

* Corresponding Author: Mahbubeh Fouladchang, Associate Professor, Educational Psychology Department, Education and Psychology Faculty, Shiraz University, Shiraz, Iran.

E-mail: foolad@shirazu.ac.ir

Tel: (+98) 7136134000

2476-5740/ (C) 2021 The Authors. This is an open access article under the CC BY-NC-ND license

(https://creativecommons.org/licenses/by-nc/4.0/). 


\section{Extended Abstract}

\section{Introduction}

The development of critical thinking through educational environments has been considered as an important and undeniable goal (Radulovic \& Stancic, 2017). Critical thinking allows people to face the many challenges of personal, educational, professional and social life more effectively (Elftahi, 2017). In a definition of critical thinking, Fation (2013) considers its main features to include purposeful and self-directed judgment that results in interpretation, analysis, evaluation, and inference. $\mathrm{He}$ believes that critical thinking is based on contextual, cognitive and methodological considerations.

Accordingly, one of the most important antecedents of critical thinking student's is the educational environment. Radulovic \& Stancic (2017) while emphasizing the need to use critical thinking skills in educational and school spaces, state that designing an educational space is important to help to the growth and development of critical thinking skills.

Kanadley (2019) also states that a learning environment that relies on the characteristics of student autonomy can affect critical thinking. Such environments are based on the theory of selfdetermination (Ryan and Desi, 2017). This theory believes that environmental support meets the basic psychological needs of individuals, including the need for competence, the need to belong and the need for autonomy, and these needs also facilitate and strengthen self-regulation of motivation (Chen and Jang, 2010).

In addition, learners' characteristics can also affect in their critical thinking. In recent years, mindfulness has come to the attention of researchers (Noone \& Hogan, 2016; Škobalj, 2018). Critical thinking depends on the individual's awareness (Halpern, 2013). In mindfulness, the person becomes aware of the mental way at all times. Mindfulness has been proposed as a non-judgmental approach to help people overcome unpleasant experiences (Zafari and Khademi Eshkezari, 2020).

On the other hand, mindfulness has also affectedof the social environment of learning. Brown and Ryan (2012) stated that social conditions can also affect mindfulness. Mindfulness is more prevalent in classrooms where students' curiosities are accompanied by a sense of security, flexibility, and participation (Hay and Sweetland, 2001). Most research in the field of mindfulness has been based on the premise that mindfulness reduces suffering, and the focus on linking mindfulness and thinking skills has been somewhat neglected in researches (Hatrow, Hooper, Mahmoud, Meyer, \& Wieger, 2016).

In general, considering the importance of critical thinking in the educational system, the factors that predict and influence the use of critical thinking skills are important. Therefore, the present study seeks to investigate the relationship between the characteristics of a supportive learning environment and critical thinking through the mediation of mindfulness in students.

\section{Method}

The research method is correlation and modeling of structural equations. The population of this study included all high school students in Shiraz city in the academic year 2019-2020. 525 students (301 girls and 224 boys) were selected by multi-stage cluster random sampling. Participants answered three questionnaires: autonomy supportive environmental scale (Assor and et al, 2002, Assor, 2012), Freiburg mindfulness questionnair (short form, Walach and et al, 2006), and California critical thinking test (Facione, 2013). Data were analyzed using structural equation modeling and AMOS software and fitness indicators.

Tools:

1. Autonomy supportive environmental Scale: To measure the characteristics of a autonomy supportive environment use the Self-report scale (Assor, Kaplan, and Ruth, 2002, Assor, 2012). This scale had 21 items that were scored on a 5 Likert scale. Assor (2012) evaluated the validity and reliability using confirmatory factor analysis and Cronbach's alpha, which had good results. In the present study, the reliability of the scale was obtained using Cronbach's alpha coefficient.

2. Freiburg Mindfulness Questionnaire (short form): Wallach, Bachhold, Batten Müllerf, Clinconch and Smith (2006) designed the short form of the Freiburg Mindfulness Questionnaire with 14 items for use in 


\section{Monthly Journal of Psychological Science}

Vol. 20, No. 107, Winter(February) 2022

the general population. Ghasemi-Jubneh and et al (2015) evaluated the short form of the Freiburg Mindfulness Questionnaire as appropriate for the Iranian society. In the present study, Cronbach's alpha coefficient of the questionnaire was equal to 0.78 , which indicates the optimal reliability coefficient of the questionnaire.

3. California Critical Thinking Test: This test was created by Fation (2013) and has two forms A and B. The resulting score includes an overall score of the subject's critical thinking and separate scores related to the five sub-skills of analysis, inference, evaluation, deductive reasoning and inductive reasoning. In Iran, Mehrinejad (1) standardized this test (form A) and presented its reliability coefficient by halving method and calculating Spearman Brown correlation coefficient of 0.88 . In the present study, Form A was also used. In addition, in this study, the reliability of the test was calculated using SpearmanBrown coefficient of 0.71 .

Table 1. Direct, indirect and total effect

\begin{tabular}{|c|c|c|c|c|c|c|c|}
\hline Predictive variable & Criterion variable & direct effect & $\mathrm{p}$ & \multicolumn{3}{|c|}{ Indirect effect } & Total effect \\
\hline & & & & $\beta$ & Error & $\mathrm{p}$ & \\
\hline autonomy supportive & mindfulness & .18 & .001 & $\overline{-----}$ & ----- & $\begin{array}{c}---- \\
\end{array}$ & .001 \\
\hline autonomy supportive & critical thinking & .18 & .001 & .05 & .021 & .038 & .001 \\
\hline mindfulness & critical thinking & .28 & .001 & ----- & ----- & ----- & .001 \\
\hline
\end{tabular}

\section{Results}

Figure 1 shows the results of the final research model, which was analyzed using AMOS software version 23 . In total, the present research model explains $13 \%$ of the variance of critical thinking.

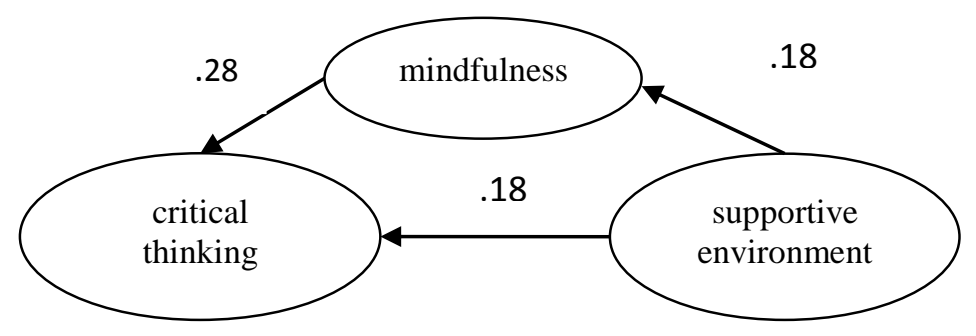

Figure 1. final research model

Research findings showed that the autonomy supportive environment has a direct and positive effect on critical thinking ( $p=0.001, \beta=0.18)$. Also, the findings indicate the direct effect of autonomy supportive environment on students' mindfulness $(\mathrm{p}<0.001, \beta=0.18)$.

In addition, that mindfulness is a positive and significant predictor of critical thinking $(\mathrm{p}=0.001$, $\beta=0.28$ ). Finally, the autonomy supportive environment influenced critical thinking $(\mathrm{p}=0.038$, $\beta=0.05$ ) through mindfulness (table 1).

In order to evaluate the fit of the research model, fit indices were calculated that the results indicated an acceptable fit of the final research model.

\section{Conclusion}

In this study, was examined the mediating role of mindfulness in the relationship between autonomy supportive environment and students' critical thinking. The results of structural equation analysis indicated that the autonomy supportive environment was a significant predictor of critical thinking. This finding is consistent with previous research on the impact of learning environments on critical thinking (Kanadli, 2019; Baghdadchi et al., 2019; Wan and Cheng, 2018; Tironeh et al., 2017; Radulovic \& Stancic, 2017; Marin \& Halpern, 2011). autonomy supportive environment encourages learners to be able to examine learning situations from different aspects, such as how to do homework and select educational topics, and provides this possibility for them.

Autonomy supportive environment also provides an opportunity to think about their own perspectives by listening to the ideas and ideas of other students and accepting their critiques, thereby enabling learners to be more involved in learning activities. In explaining this finding, it can be stated that among different educational environments, such environments according to the expressed characteristics can strengthen critical thinking in students and have the greatest impact on critical thinking.

In addition, the results showed that the autonomy supportive environment had a significant relationship 
with mindfulness. This finding was also consistent with the findings of Brown and Ryan (2012) and Hassannia and Fooladcheng (2015). Autonomy supportive environment provide the conditions for the learner to be present in the learning situation now and now. From the point of view of self-determination, which underlies the learning environment that supports self-discipline, the learner can be taught the skill to consider different situations, situations and ideas in the learning environment and to make informed choices.. In this way, the learner can control his thoughts and behavior and be able to control unrelated factors.

Also, based on the paths of the structural equation model, mindfulness could be a significant predictor of critical thinking. This finding is also consistent with past findings (Escobalage, 2018; Holland et al., 2017; Noone and Hogan, 2016). Noone (2016) showed that mindfulness can positively and significantly predict critical thinking. Škobalj (2018) also stated that mindfulness can play a fundamental role in the development and use of critical thinking in learners. In order to explain this finding, it can be stated that the ability of mindfulness helps learners to make better use of the ability to ask questions about the learning situation by attending the moment of learning or problem solving. In many schools, there is an overemphasis on information retention and repetition, and students are graded according to the amount of information they remember and are able to replicate. The purpose of mindfulness training is not to make learners look for pleasant emotions and to avoid unpleasant things. Mindfulness is the basis for deep observation and understanding of the reasons and conditions necessary for the occurrence of a particular phenomenon that is observed in critical thinking about the subject (Škobalj, 2018).
Finally, the results showed that mindfulness could play a mediating role between the autonomy supportive environment and critical thinking. Hassannia and Fooladcheng (2015) also showed that mindfulness can play a mediating role in the relationship between constructive learning environment and academic burnout. In addition, as observed, the relationship between learning environment and mindfulness (Brown and Ryan, 2012; Hassan Nia and Fooladcheng, 2015) and mindfulness with critical thinking (Scobalge, 2018; Holland et al., 2017; Noone \& Hogan, 2016) was confirmed in previous studies. According to the findings of the present study, it seems that the autonomy supportive environment plays an important role in the development of mindfulness and critical thinking. But as we have seen in the study of research paths, one of the basic questions that has always been of interest to education professionals is how to awaken the desire for critical thinking in students and guide students towards critical thinking.

\section{Ethical Considerations}

Compliance with ethical guidelines: This article is taken from the $\mathrm{PhD}$ of the first author in the field of educational psychology in the Faculty of Educational Sciences and Psychology of Shiraz University of Iran. Research-related issues in the statistical community have been issued by the General Directorate of Education of Fars Province.

Funding: This study was conducted as a $\mathrm{PhD}$ thesis with no financial support.

Authors' contribution: The first author was the senior author, the second were the supervisors and the third and forth was the advisors.

Conflict of interest: the authors declare no conflict of interest for this study.

Acknowledgments: Thanks to the supervisor and advisors of this research as well as school manegers and students who helped in conducting this research. 


\section{بررسى نقش واسطهاى ذهن آحاهى در رابطه بين محيط حامى خودييروى و تفكر انتقادى در دانش آموزان}

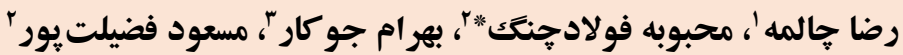

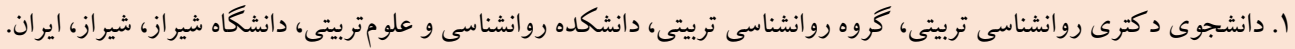

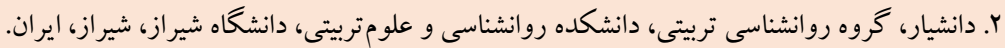

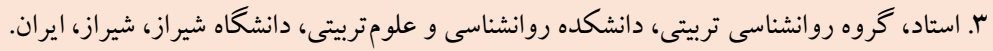

جكيله

زمينه: تفكر انتقادى از سازههاى مهم و قابل تو جه در سالهاى اخير بوده است؛ اما شناسايى متغيرهاى بيشبينى كننده آن در قالب يك مدل

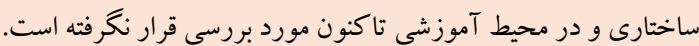

هدف: هدف اين يزوهش بررسى نقش ذهن آكاهى بهعنوان متغير واسطهاى در رابطة بين محيط حامى خودييروى و تفكر انتقادى بود. روش: يُزوهش حاضر توصيفى و از نوع همبستخى و معادلات ساختارى بود. جامعه اين يُروهش شامل همهٔ دانش آموزان متوسطه دوم شهر

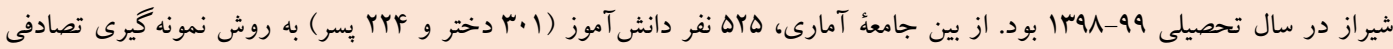

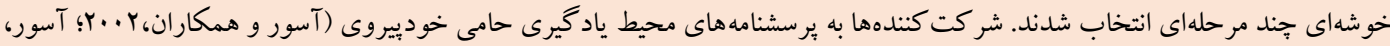

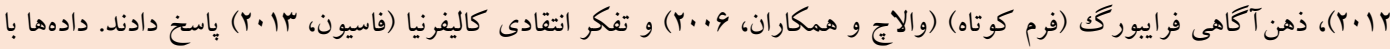

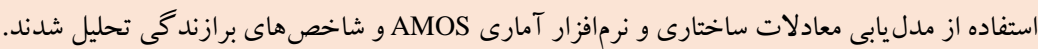
يافته ها: نتايج نشان دادند كه مدل بيشنهادى از برازش خوبى برخوردار است. ضرايب مسير مستقيم بيانگر اين بود كه محيط حامى خودييروى

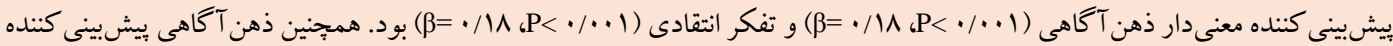

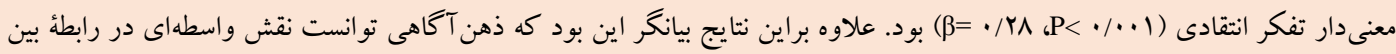
محيط حامى خودييروى با تفكر انتقادى ايفا نمايد. نتيجه كيرى: ويز گىهاى بافتى ماند محيط حامى خودييروى در كنار عوامل درون فردى نظير ذهن آكاهى، نقش مهمى در تفكر انتقادى

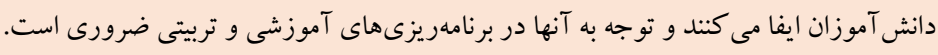

مشخصات مقاله

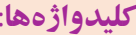

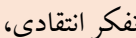

ذهن آكاهى،

محيط حامى خودييروى، دانش آموزان

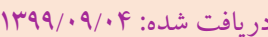

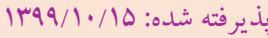
| منتشر شده: |• | |

* نويسنده مسئول: محبوبه فولادجنك؛، دانشيار، گروه روانشناسى تربيتى، دانشكده روانشناسى و علومتريتى، دانشكاه شيراز، شيراز، ايران. رايانامه: foolad@shirazu.ac.ir

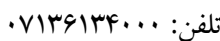


نظريه خودتعيين گُرى هستند (دسى و رايان، 19 (r). اين نظريه بر اين باور است كه حمايتهاى محيطى سبب برآورده شدن نيازهاى بنيادين

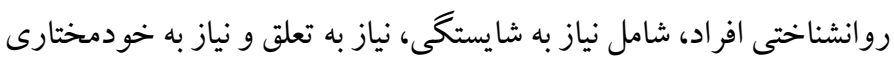

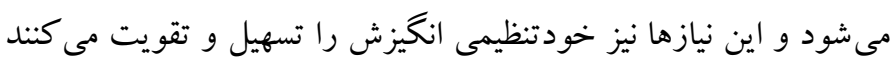

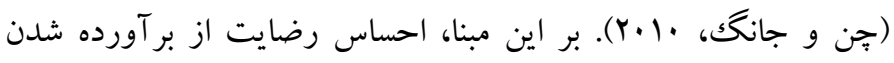

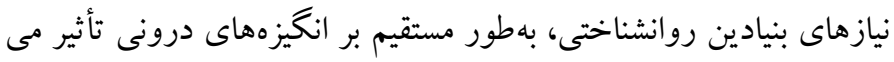

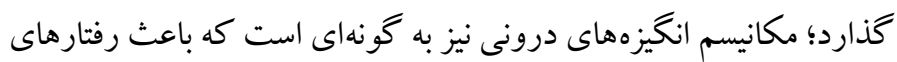

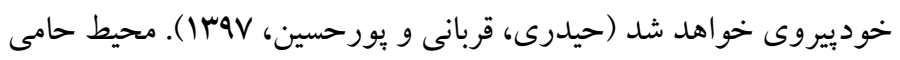

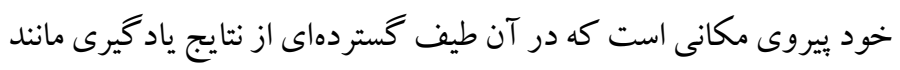
توسعهُ يكك سبك زندگى فعال، دست يابى به مهارت هاى حر كتى و يرورش ارزشهاى مثبت حاصل مىشود (ميرزايى فندخت، درتاج، سعدىيور،

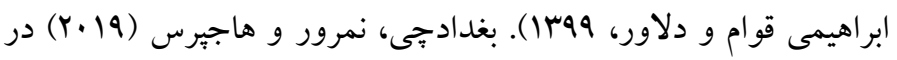

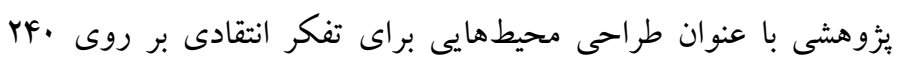

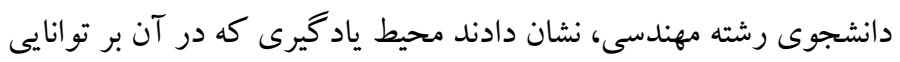

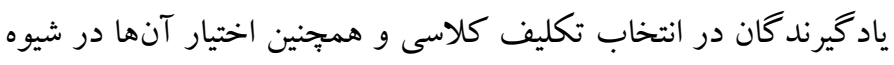
اجراى تكاليف تأكيد مى شود مى تواند تفكر انتقادى ياد گيرند

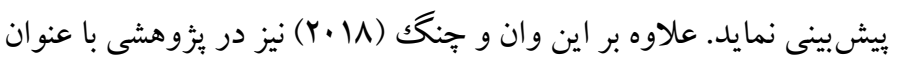

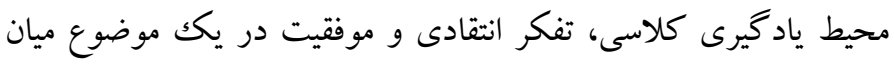

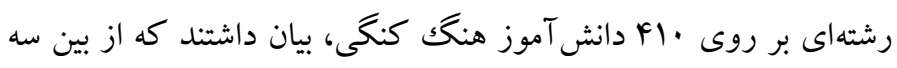

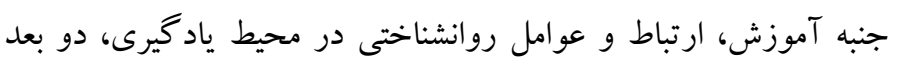

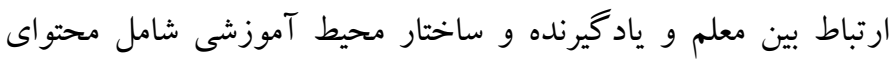

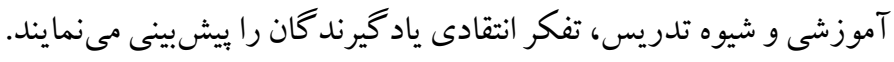

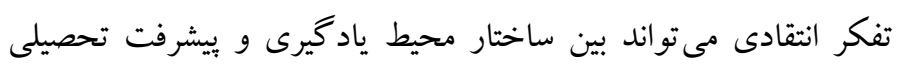

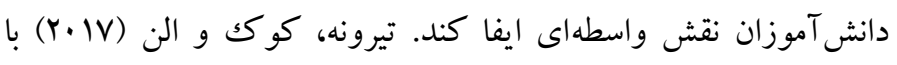
مقايسه دو ساختار آموزشى مبتنى بر آموزش مستقيم و آموزش برمبناى إنى

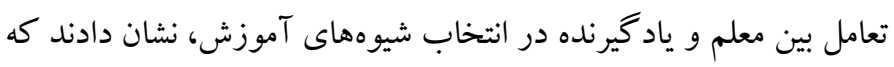

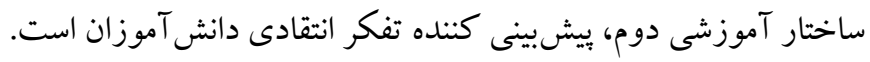

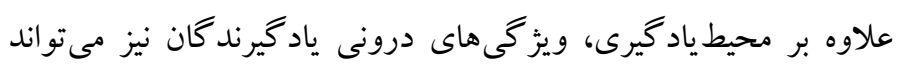

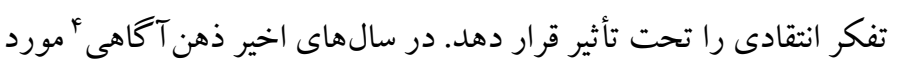

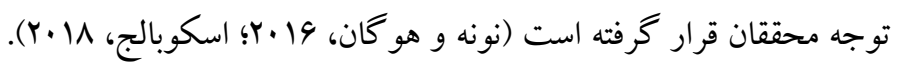

${ }^{3}$. self-determination theory

${ }^{4}$. mindfulness
مقلفمه گُشتر تفكر انتقادى' از طريق محيطهاى آموزشى در عصر حاضر، به

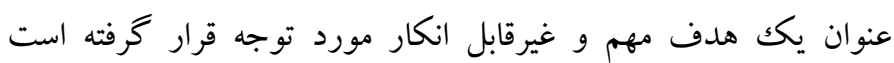

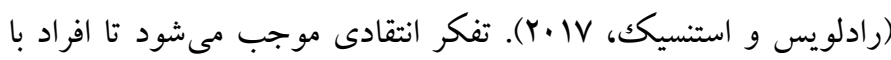
جالش هاى متعلد زندگى شخصى، تحصيلى، شغلى و اجتماعى مو اجههى

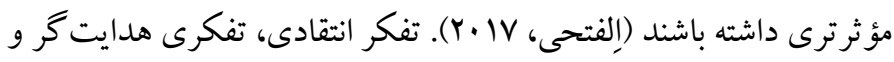
منضبط است كه مى كوشد از راه استدلال، به شيوهاى منصفانه، به بالاترين سطح از كيفيت در فرآيند تفكر دست يابد. اهميت به كار گيرى تفكر راهر

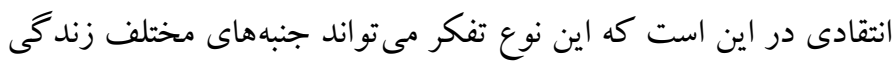

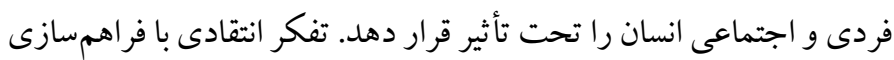

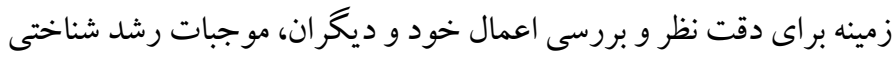
و با بهينهازى و افزايش تعاملات، زمينهساز رشد اجتماعى مى شودرد.

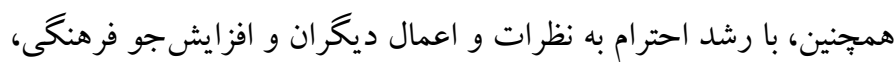

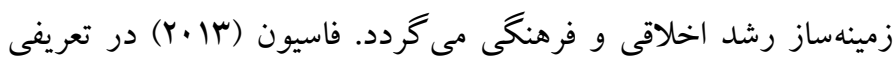

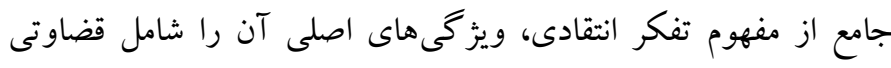
هدفمند و ناظر بر خود كه ييامد آن تفسير، تحليل، ارزيابى و نيز استنتاج است مى داند. او بر اين باور است كه تفكر انتقادى بر ملاحظات بافتارى،

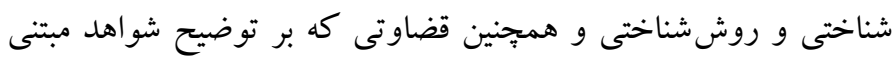

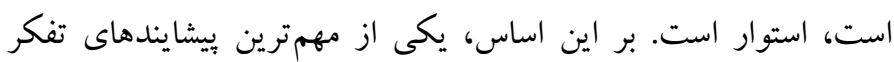

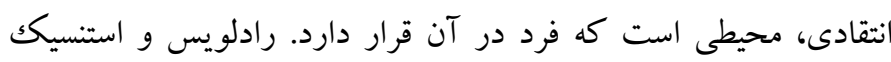

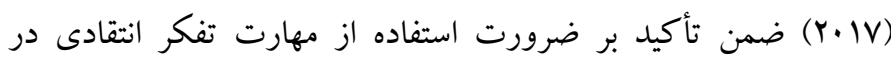

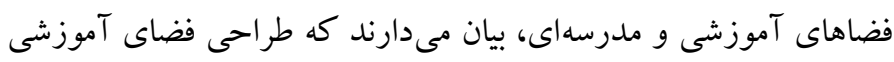

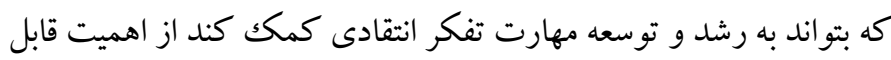
توجهى برخوردار است. اين محققان همسو با مارين و هالبرن (Yll)

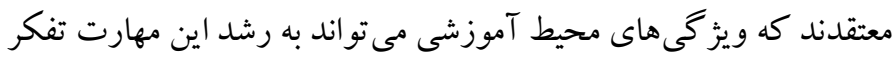
بيانجامد. كانادلى (Y.19) نيز بيان مىدارد كه محيط ياد گيرى كه بر ويزگىهاى

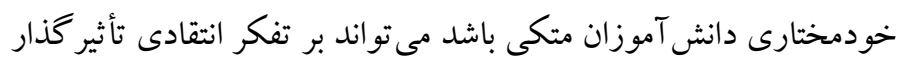

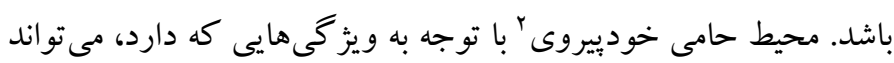

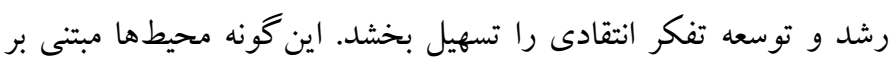

1. critical thinking

${ }^{2}$. autonomy supportive environmental 
باشند، به گُنهاى كه اداركك محيط يادگيرى بهصورت درگير بودن

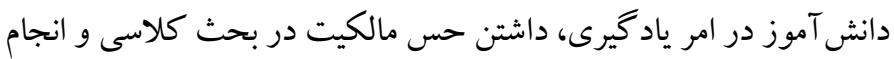

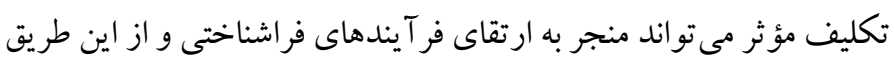

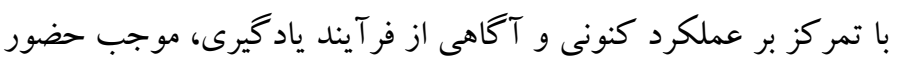
آكاهانه ذهن دانش آموز شود. اغلب بثزهشها در حوزه ذهن آكاهى بر اين مبنا استوار بودهاند كه ذهن دهن آكاهى موجب كاهش رنج مىشود و تمركز بر بيوند ذهن آكاهى و ونى

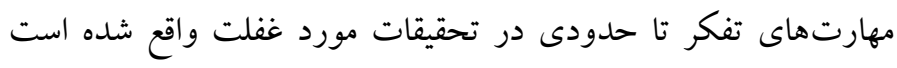

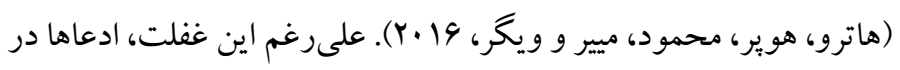

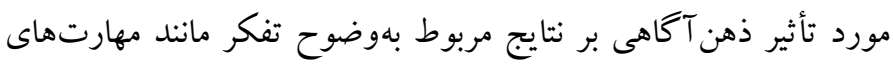

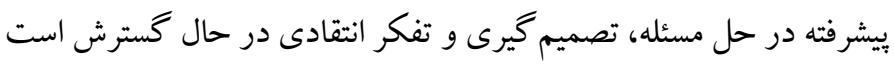

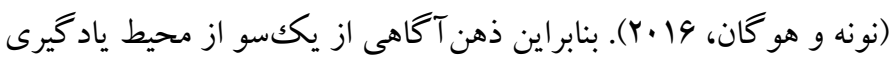
تأثير مى بذيرد و از سوى ديخر مى تواند بر كسترش تفكر انتقادى اثر خذار

باشد.

بهطور كلى، با توجه به اهميت تفكر انتقادى و جايگاه آن در نظام

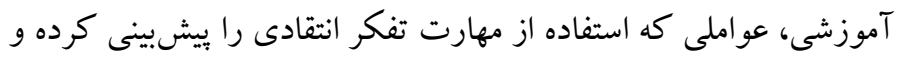

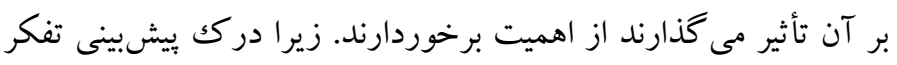

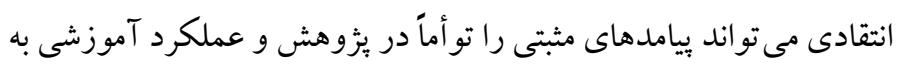

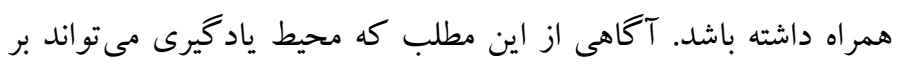

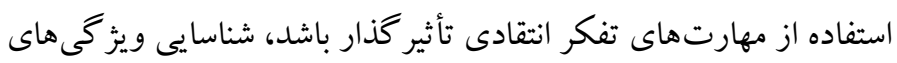

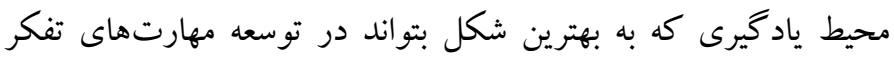

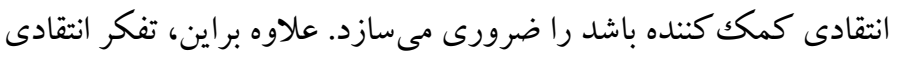

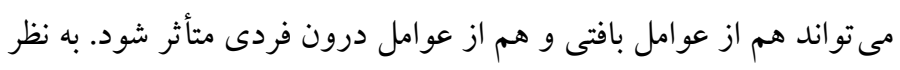
مىرسد كه عوامل درون فردى مى توانند در رابطه بين ويز گَى هاى محيط

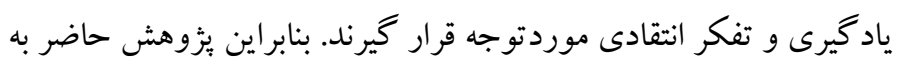

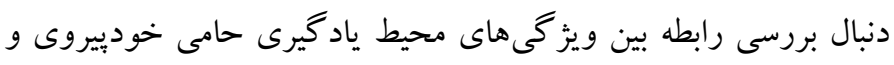

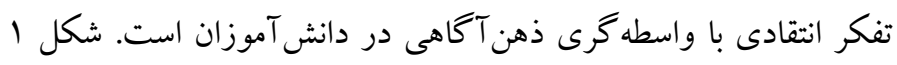
روابط بين متغيرهاى بثزوهش رابه تصوير كشيده است.
تفكر انتقادى به آكاهى فرد وابسته است، آكاهى از اينكه يك مهارت تفكر ويزه، فرد را قادر مىسازد تا فر آيندهاى فكرى خود رابه را ارزيابى و كنترل

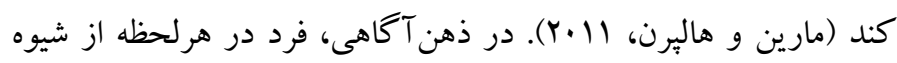

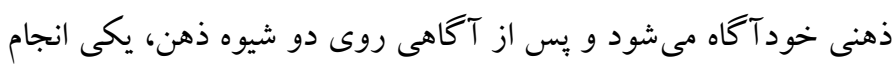

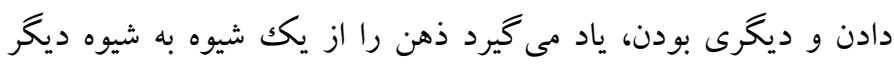

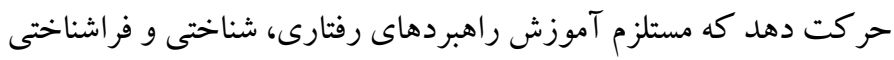

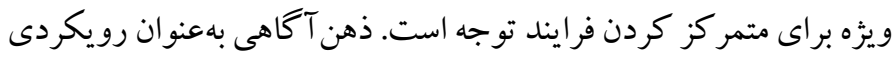

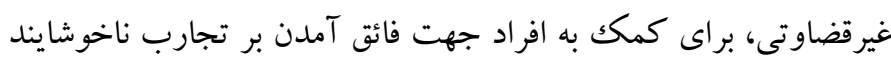

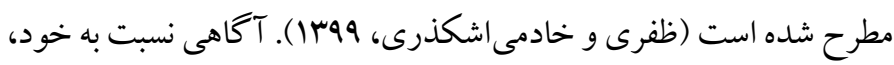

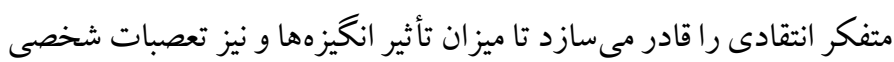

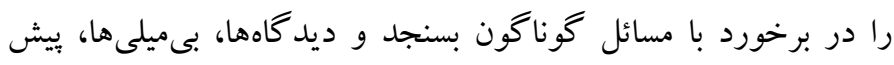

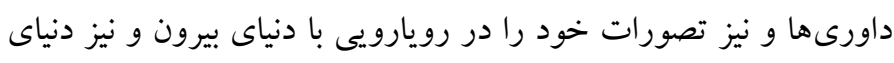

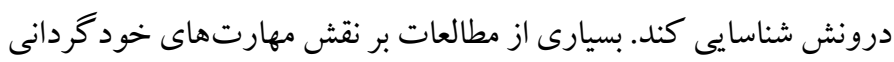

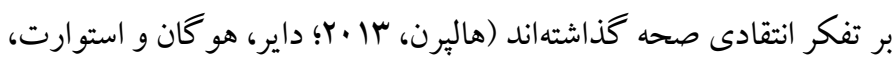

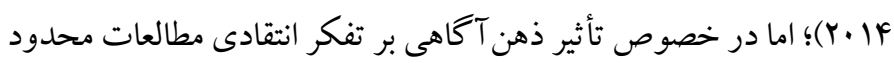

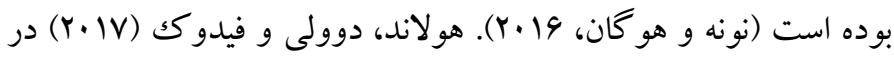
يُروهشى آزمايشى به بررسى تأثير ذهن آكاهى و مراقبه بر تفكر انتقادى

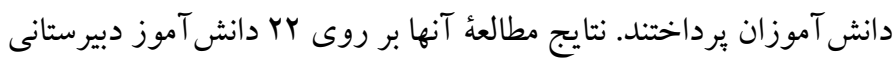

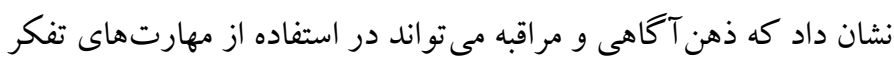
انتقادى مؤثر باشد. اين محققان بيان داشتند كه سن، جنس ودر و و قوميت

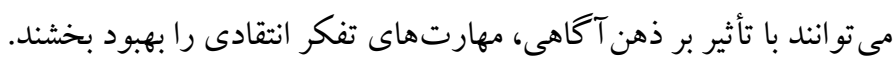
از سوى ديخر ذهن آكاهى از محيط اجتماعى ياد گيرى نيز تأثير مى يذيرد.

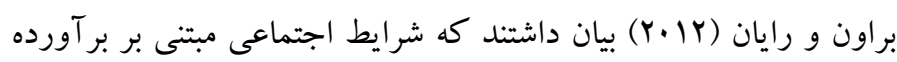

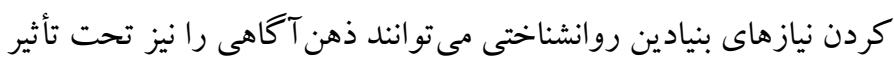
قرار دهند. ذهن آكاهى در كلاس هايى بيشتر است كه كنجكاوىهاى دواس دانش آموزان بااحساس امنيت، انعطاف و مشاركت همر اه شود، زيرا در اين كونه

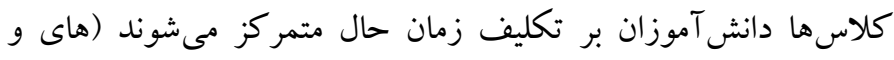

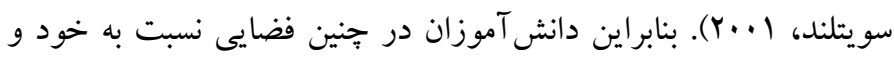

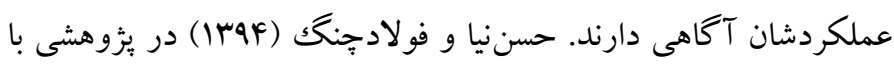

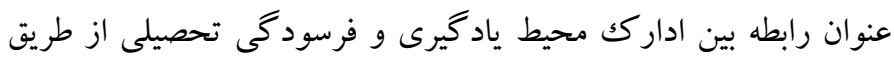
واسطه گرى ذهن آكاهى، بر روى ه.r دانش آموز دختر متوسطه، مشاهده

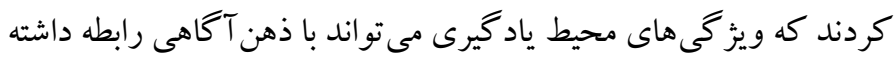


نيز، ضريب آلفاى كرونباخ براى مقياس هاى فرصت انتخاب، فرصت نقد و

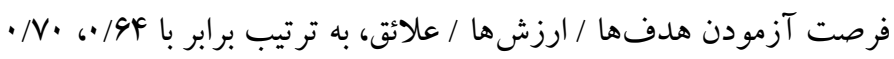

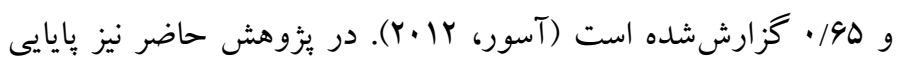

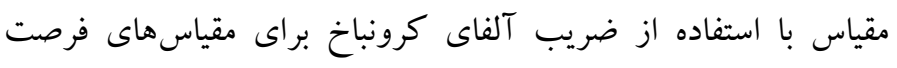

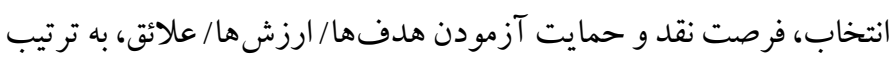

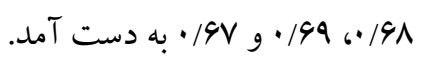

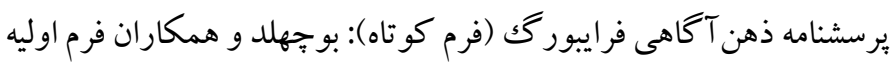

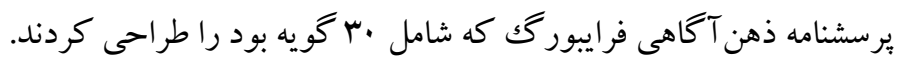
والاج، باجهلد، باتنمولرف، كلين كنجت و اسميت (Y.4. (Y) فرم كو تاه

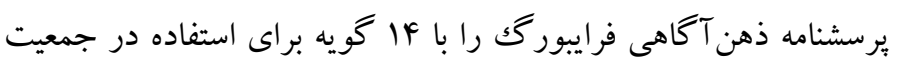
عمومى طراحى كردند. فرم بلند يرسشنامه ذهن آكاهى فرايبورگك بيشتر براى اجرا در كروههايى مناسب است كه با فرهنگك بودائى و و اعمال

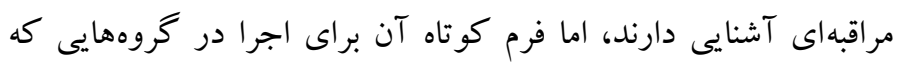

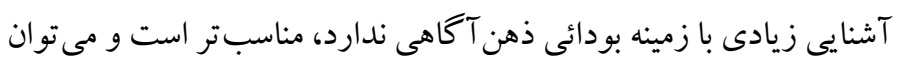

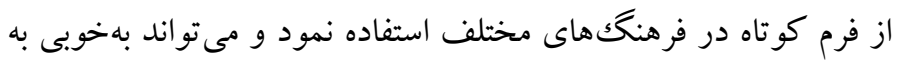

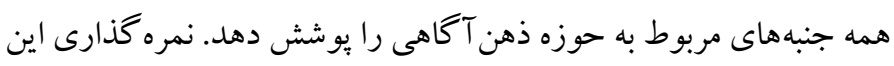

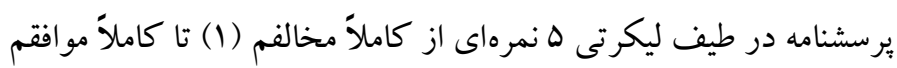

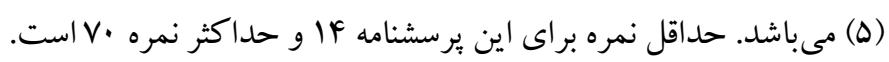

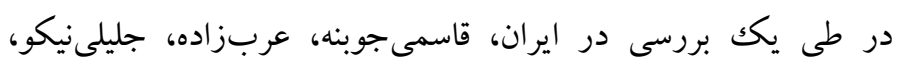

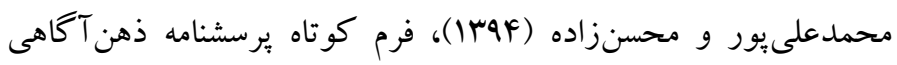

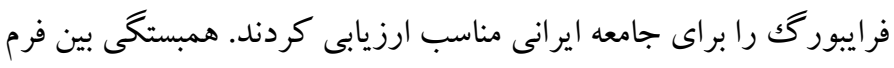

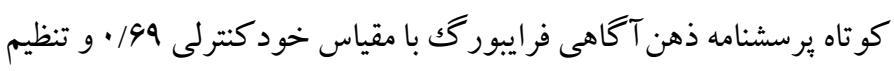
هيجانى 1/1 • مناسب و معنى دار بود. نتايج مدل تحليل عاملى تأييدى نيز

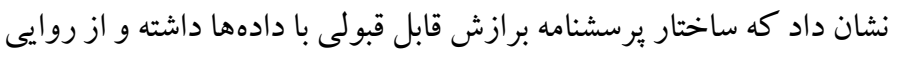
عاملى مطلوبى برخوردار است و كلئ شاخص هاى نيكويى برازش، مدل

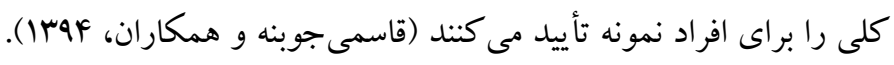

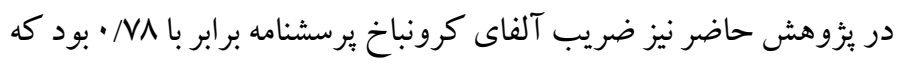
نشانكر ضريب پايايى مطلوب يُ يرسنامه بود.

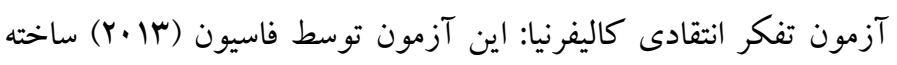

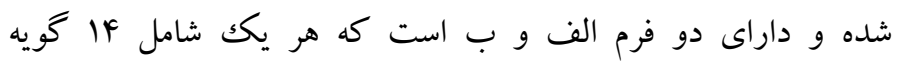

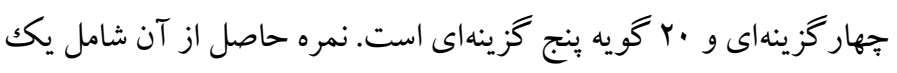
نمره كلى تفكرانتقادى آزمودنى و نمرههاى جداكانه مربوط به ينج خرده بنه

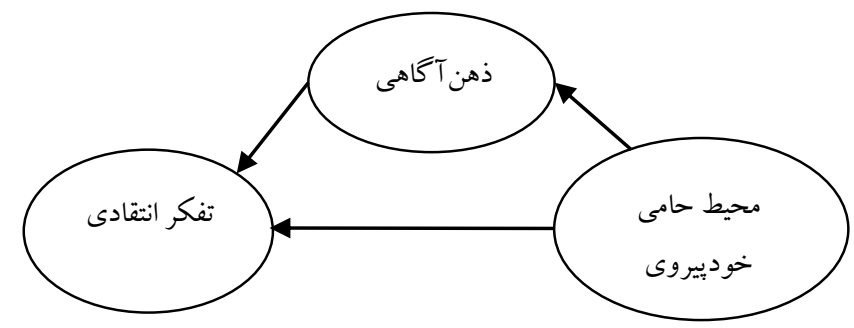

شكل ا. مدل مفهومى ثئوهش

روش

الف) طرح هثوهش و شركت كنند كان: طرح يزوهش حاضر توصيفى

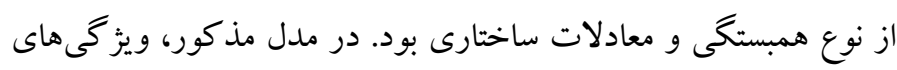

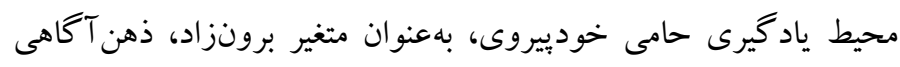

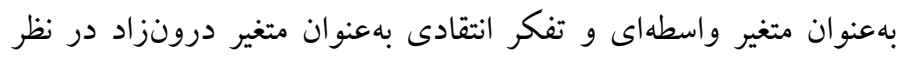

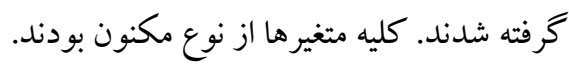
جامعهُ مورد مطالعه را دانش آموزان دورهُ متوسطة دوم شهر شيراز كه در برد

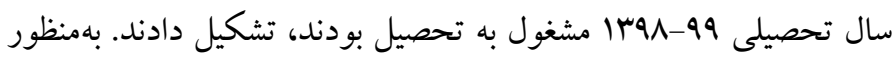

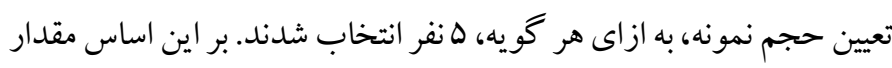

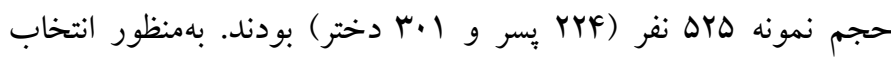

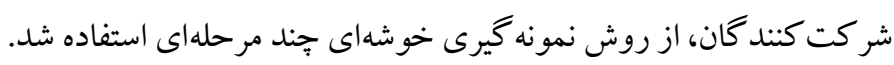

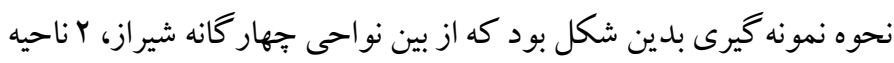

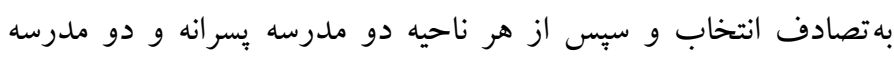
دخترانه و از هر مدرسه دو كلاس بهتصادف انتخاب و تمامى دانش آموزان اين كلاس ها به برسشنامهاى مورداستفاده در يثوهش بـاسخ دادند.

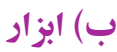
مقياس محيط ياد گيرى حامى خودييروى: براى سنجش ويز گىهاى محيط

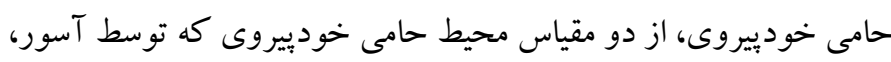

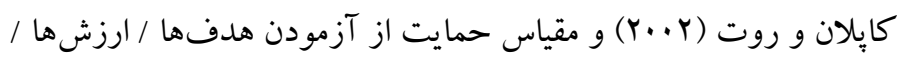
علائق كه توسط آسور (r (Y. ساخته شده بود، استفاده شد. اين دو مقياس در مجموع ا Y گويه داشتند كه در طيف ليكرت يُنجدرجهاى از كاملاً

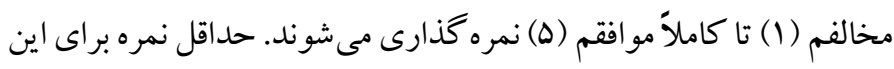

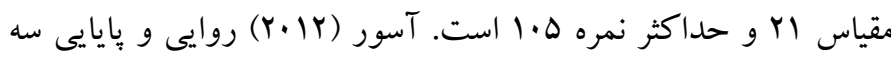
مقياس را با استفاده از روشهاى تحليل عامل تأييدى و آلفاى كرونباخ

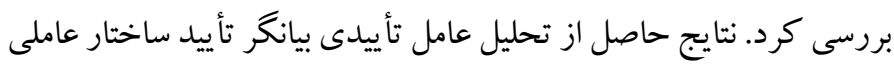

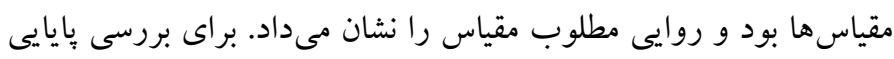


معادلات ساختارى استفاده شد. براى تعيين نقش واسطه گرى متغيرها نيز

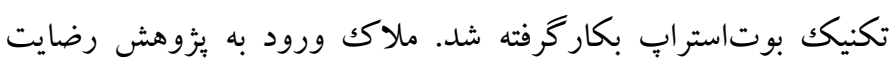

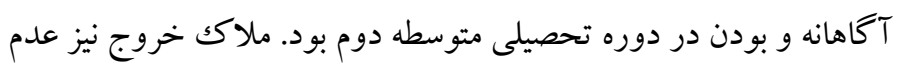

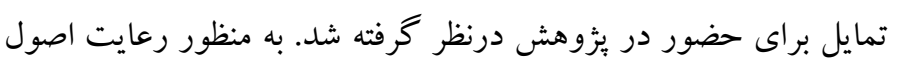

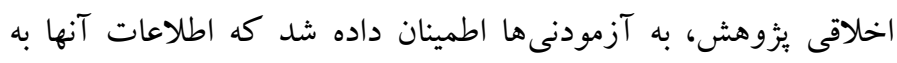

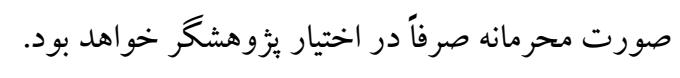

يافته ها در جدول ا، اطلاعات جمعيتشناختى شركت كنند گان بُزوهش آورده شده است. در جدول r شاخصهاى توصيفى متغيرهاى يزوهش و در

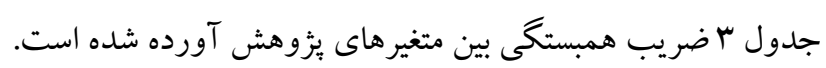

\begin{tabular}{|c|c|c|c|}
\hline درصد & فراوانى & & \\
\hline Fr & YYF & يسر & \multirow{2}{*}{ جنسيت } \\
\hline$\Delta V$ & $r \cdot 1$ & دختر & \\
\hline$\Delta G / \Gamma$ & rqD & 19 & \multirow{3}{*}{ سن } \\
\hline$F Y / F$ & rrr & IV & \\
\hline $1 / r$ & $v$ & 11 & \\
\hline 4. & MID & دهم & \multirow{2}{*}{ پايه تحصيلى } \\
\hline f. & rI. & يازدهم & \\
\hline
\end{tabular}

مهارت تحليل، استنباط، ارزشيابى، استدلال قياسى و استدلال استقرايى

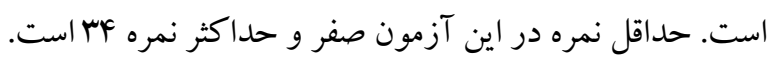

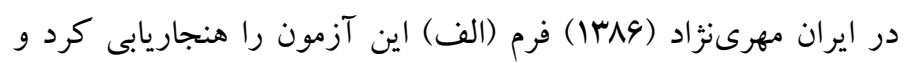

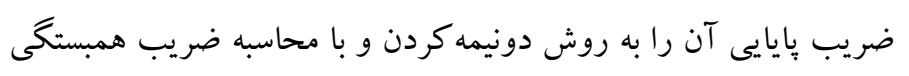

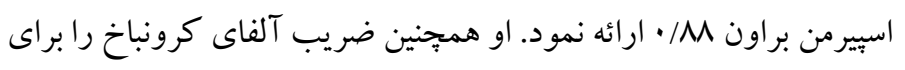

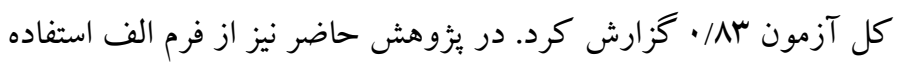

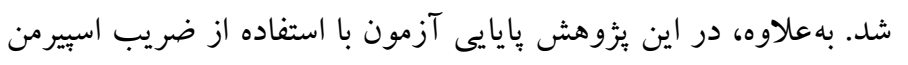
براون MI/ • محاسبه شد. بهنظور انجام تحقيق حاضر، ابتدا مجوزهاى قانونى لازم از آموزش و و ماند

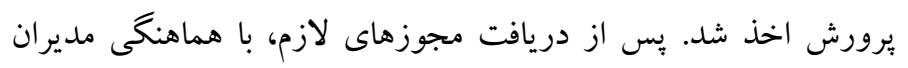
مدارس، محقق در كلاسها حضور يافت. يس از جلب رضايت آكاهانه

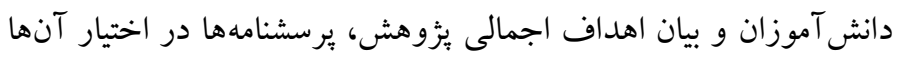
قرار گرفت. براى تجزيه و تحليل اطلاعات و جهت بررسى مدل بيشنهادى يزوهش، از

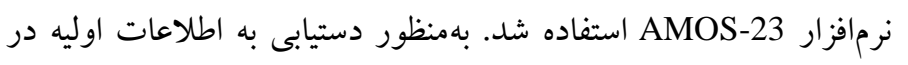
مورد متغيرهاى اندازه گيرى شده، شاخصهاى آمارى نظير ميانگين و

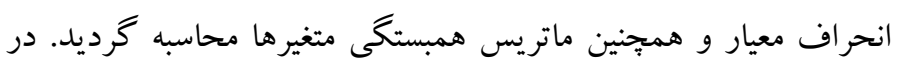

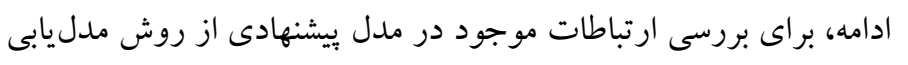

جدول r. شاخصهاى توصيفى متغيّر هاى ثئوهش

\begin{tabular}{|c|c|c|c|c|c|c|}
\hline تورم واريانس & تحمل & $\mathrm{p}$ & zالمو گرافz & انحر اف معيار & ميانگين & \\
\hline 1/A9 & $\cdot / V r$ & 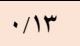 & $\cdot / 9$ & $9 / 91$ & $r \cdot / \cdot q$ & 1. فرصت انتخاب \\
\hline$r / \cdot m$ & .194 & $\cdot / \Delta 1$ & $\cdot / M$ & $\mathrm{~V} / \mathrm{r}$. & $19 / 94$ & r. فرصت نقد \\
\hline l/Ar & $\cdot / \Delta 9$ & $\cdot / F \Delta$ & .199 & $\mathrm{~V} / \mathrm{l}$ & $r \cdot / l$. & r. حمايت آزمودن هدفها \\
\hline $1 / \pi V$ & $\cdot / \mathrm{WV}$ &.$/ 94$ & $\cdot / 191$ & $\mid F / N$ & $\Delta F / T \Delta$ & F. ذهن آكاهى \\
\hline--- & --- & $\cdot / 11$ & $\cdot / 419$ & $r / \Delta 9$ & N/9Y & هـ تحليل \\
\hline--- & --- & $\cdot / 14$ & •/AIr & $f / D$ & $\Lambda / V r$ & 9. استنباط \\
\hline--- & --- & $\cdot / \Delta \Delta$ & $\cdot / 9 F 1$ & $r / 94$ & $9 / K Y$ & V V. ارزشيابى \\
\hline--- & --- & $\cdot / \cdot \wedge \mathrm{V}$ & $1 / \cdot r \mu$ & $f / \mu$ & N/qF & ᄉ استدلال قياسى \\
\hline--- & --- & $\cdot / 44$ & $\cdot / 9 \& V$ & $1 / V 9$ & r/Ar & 9. استدلال استقر ايى \\
\hline
\end{tabular}

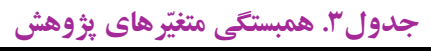

\begin{tabular}{|c|c|c|c|c|c|c|c|c|}
\hline$\wedge$ & $\checkmark$ & 4 & $\Delta$ & F & $r$ & $r$ & 1 & متغيرها \\
\hline & & & & & & & --- & 1. فرصت انتخاب \\
\hline & & & & & & --- & $\cdot / 9 \cdot * *$ & r. فرصت نقد \\
\hline & & & & & --- &.$/ 91^{* * * \%}$ & $\cdot / \Lambda \varphi^{* * * *}$ & r. حمايت آزمودن هدفها \\
\hline & & & & --- & $\cdot / I V^{*}$ & $\cdot / / V^{*}$ & $\cdot / \Lambda^{* * *}$ & f. ذهن آ كاهى \\
\hline
\end{tabular}




\begin{tabular}{|c|c|c|c|c|c|c|c|c|}
\hline$\wedge$ & $v$ & 9 & $\Delta$ & f & $r$ & r & 1 & متغيرها \\
\hline & & & --- & $\cdot / \mu \cdot * * *$ & $\cdot / r^{* * * *}$ & $\cdot / r Y^{* * * *}$ & $\cdot / \mu \cdot * *$ & هـ تحليل \\
\hline & & -- & $\cdot / \sqrt{ } 9^{* * *}$ & $\cdot / r \Delta^{\text {*** }}$ & $\cdot / \Lambda^{* *}$ &.$/ 19^{* * *}$ & $\cdot / r \Delta^{* *}$ & 9. استنباط \\
\hline & --- & $\cdot / \Delta r^{* * * *}$ & $.19 \Lambda^{* *}$ & $\cdot / \Lambda^{* * *}$ & $\cdot / F^{*}$ & $\cdot / / F^{*}$ & $\cdot / 1 r^{\circ}$ & V. ارزشيابى \\
\hline--- & $\cdot / \Delta \Delta^{* * * *}$ & $\cdot / \Delta \Delta^{* * * *}$ & $\cdot / N^{* * *}$ & $\cdot / r \cdot \%$ & $\cdot / F^{\circ}$ & $\cdot / / V^{*}$ & $\cdot / r \Delta^{* * *}$ & ^. استدلال قياسى \\
\hline$\cdot / \mu F * n$ & $\cdot / \Delta F^{* * * x^{*}}$ & $\cdot / V I^{* * * *}$ & $\cdot / \Delta 9^{* * *}$ & · & $\cdot / 10^{*}$ & $\cdot / 11^{*}$ & $\cdot / / r^{*}$ & ه. استدلال استقرائى \\
\hline
\end{tabular}

${ }^{*} \mathrm{p}<\cdot / \cdot 1, \mathrm{p} p<\cdot / \cdot \Delta$

جدول ع. ضرايب استاندارد اثرات مستقيم، غير مستقيم و كل متثيّر هاى ثئوهش

\begin{tabular}{|c|c|c|c|c|c|c|c|c|c|}
\hline اثر كل & & & رغير مستقيم & & & سطح معنى دارى & اثر مستقيم & متغير ملاكك & متغير ييش بين \\
\hline & $\mathrm{P}$ & حد بالا & حديايين & خطا & $\beta$ & & & & \\
\hline--- & --- & -- & -- & $\%$ &.$/ 11$ &.$/ \cdots 1$ & $\cdot / 1 \wedge$ & ذهن آكاهى & محيط حامى خودييروى \\
\hline.$/ 19$ &.$/ \cdot 11$ & $\cdot / \cdot r \mid$ & $.1 \cdot 0$ & $\% / \cdot 1$ & $\cdot / 1 \wedge$ &.$/ \cdot 1$ & $\cdot / \Lambda$ & تفكر انتقادى & محيط حامى خودييروى \\
\hline--- & --- & --- & --- & $\cdot / \cdot 1$ & $\cdot / Y \Lambda$ &.$/ \cdots 1$ & $\cdot / r \wedge$ & تفكر انتقادى & ذهن آكاهى \\
\hline
\end{tabular}

آماره بايد در بازه إ تا ه/ه قرار كيرد كه در اين بثروهش اين آماره برابر با 1991 بود و نشانكر تأيد شدن اين بيشفرض بود. در شكل ب نتايج مربوط به مدل نهايى ثئوهش كه با استفاده از نرمافزار AMOS مىشود، در مجموع مدل يثوهش حاضر سا درصد از واريانس تفكر انتقادى را تبيين مى كند.

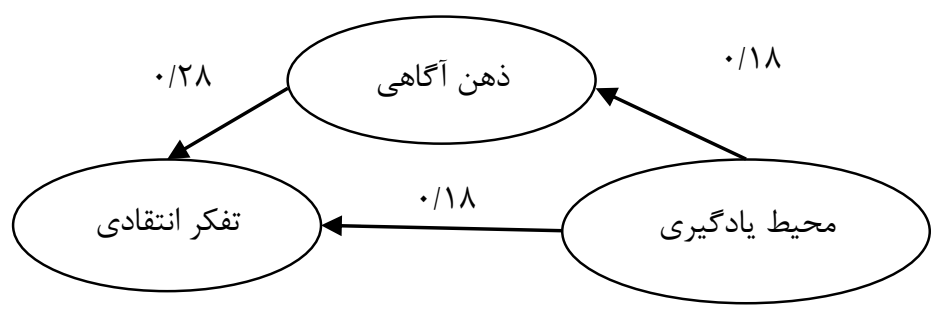

شكل". مدل آزمون شده رابطة ساختارى بين محيط حامى خود يبروى و تفكر انتقادى با واسطه كرى ذهن آناهنى

اثرات مستقيم، غير مستقيم و كل متغيرهاى يثوهش در جدول F كزارش شده است. يافته هاى يثزوهش در خصوص اثر مستقيم محيط حامى خودييروى بر تفكر انتقادى؛ نشان مىدهد كه محيط حامى خودييروى اثر

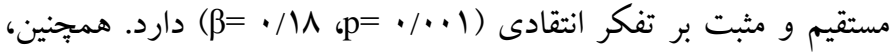
يافته ها بيانكر اثر مستقيم محيط حامى خودييروى بر ذهن آكاهى در دانش

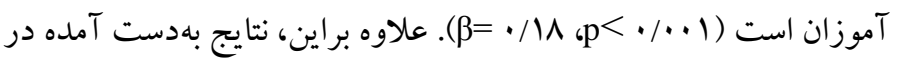
مورد تأثير ذهن آكاهى بر تفكر انتقادى، بيانكر آن است كه ذهن آكاهى

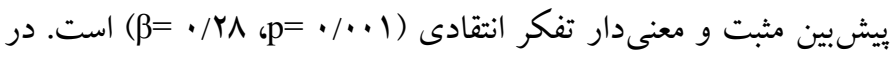

قبل از ارائه نتايج آزمون مدل ساختارى، مفروضههاى مدليابى معادلات ساختارى بررسى شد. در ابتدا با استفاده از روش آمارى كولمو گروف اسميرنوف نرمال بودن دادهها مورد بررسى قرار گرفت و تأييد شد (جدول Y). علاوه بر اين به منظور بررسى خطى بودن رابطه بين متغيرها از نمودار ير اكنش استفاده شد (شكل Y).

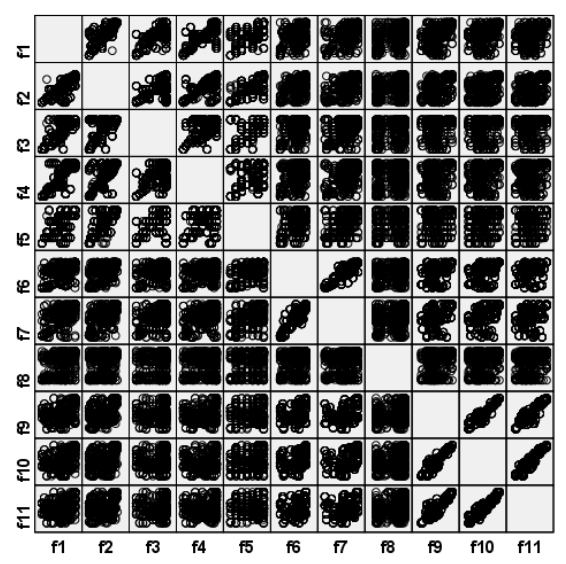

شكل r. نمودار براكنش رابطه بين متغيرها

از ديخر مفروضات مورد بررسى براى انجام مدليابى معادلات ساختارى

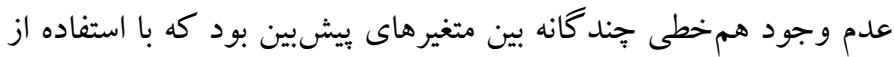

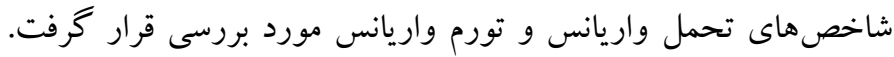

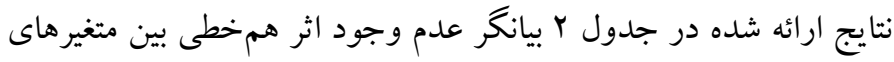

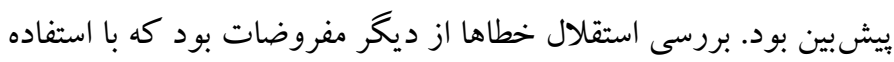

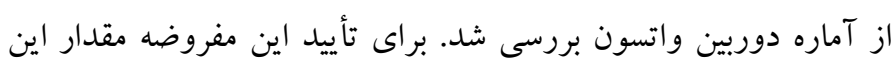


انتقادى داشته باشند. در همين راستاو وبراساس نظريه سيستمهاى بوم شناختى

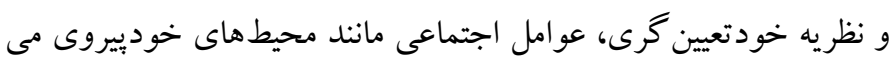

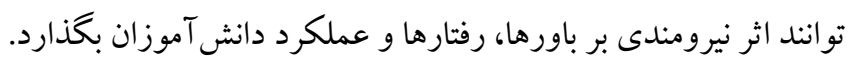

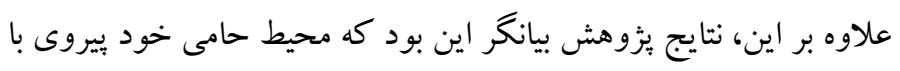

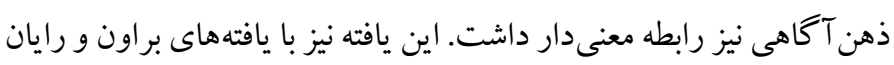

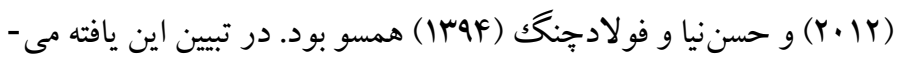
توان بيان داشت كه هر سه بعد فرصت نقد، فرصت انتخاب و حمايت

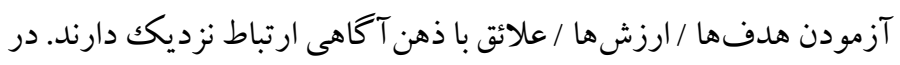

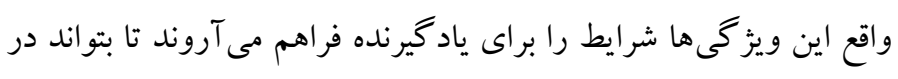

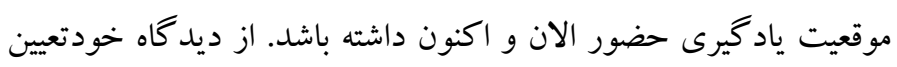

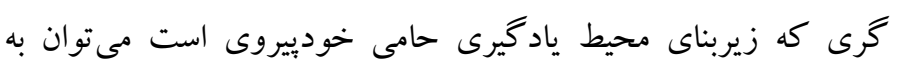

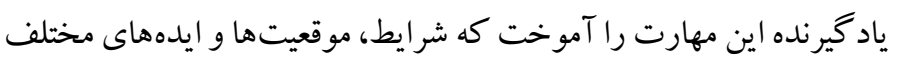
را در محيط ياد گيرى در نظر بخيرد و بهطور آكاهانهاى دست به انتخاب

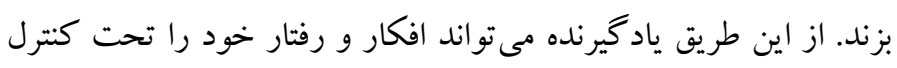
در آورد و براى مهار عو امل نامرتبط توانمند شود. ذهن آكاهى نيز بـ به دئ دنبال

$$
\text { دستيابى به اين توانيى است. }
$$

همجنين بر اساس مسيرهاى مدل معادلات ساختارى، ذهن آكاهى نيز

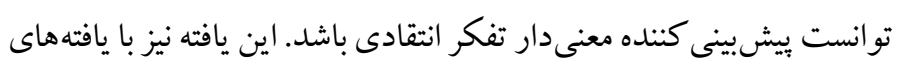

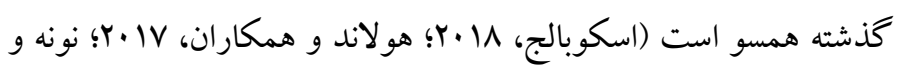

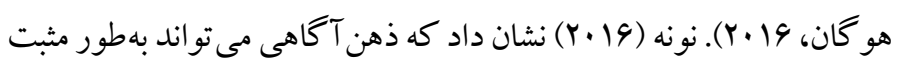

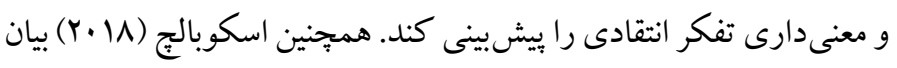

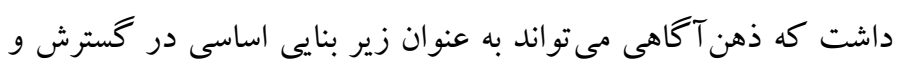

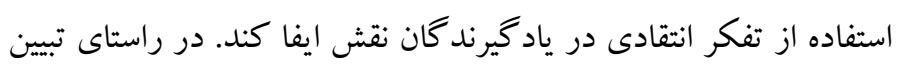

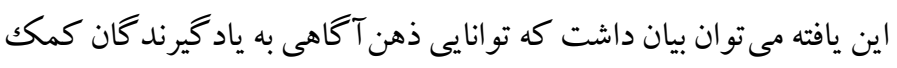

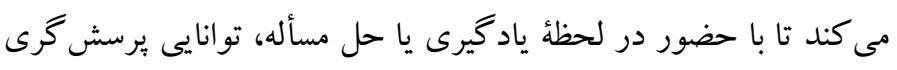

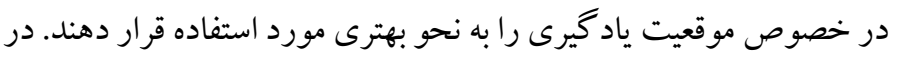

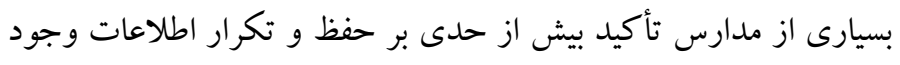
دارد و دانش آموزان با توجه به ميزان اطلاعاتى كه به ياد مى آورند و قادر

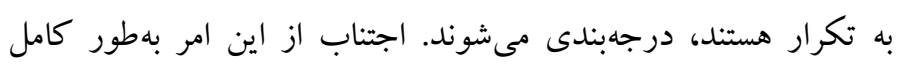

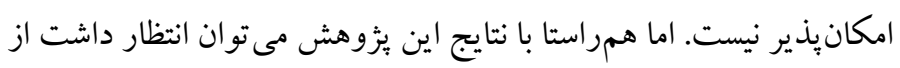

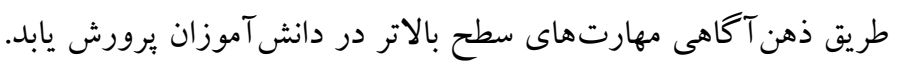
هدف استفاده از ذهن آكاهى قطعاً بيشتر از مقابله ساده با استرس و روسيد درن
نهايت، محيط حامى خودييروى با واسطه ذهن آكاهى بر تفكر انتقادى ( اثر كذار است.

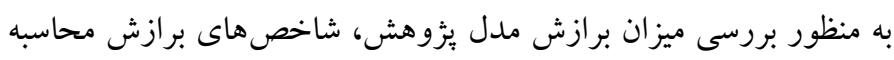

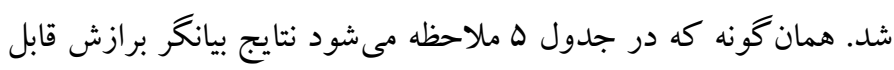
قبول مدل نهايى بثزوهش حاضر است.

\begin{tabular}{|c|c|c|c|c|c|}
\hline AGFI & GFI & IFI & CFI & $\mathrm{X} 2 / \mathrm{df}$ & شاخصها \\
\hline.$/ 91$ &.$/ 99$ & . $/ 94$ & $\cdot / 9 \Delta$ & $r / 9 T$ & مقادير \\
\hline
\end{tabular}

بحث و نتيجه تيرى

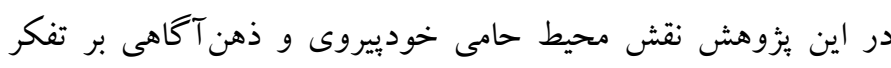

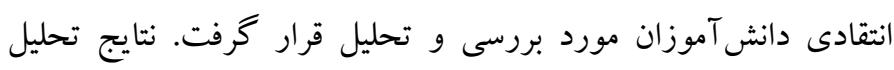

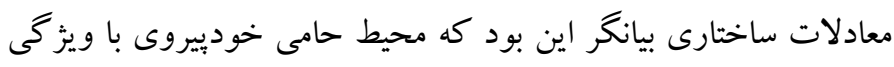

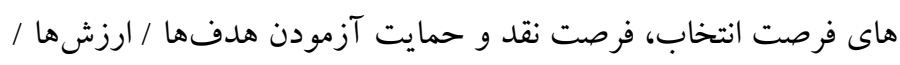

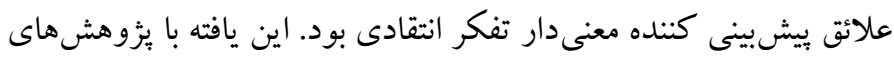

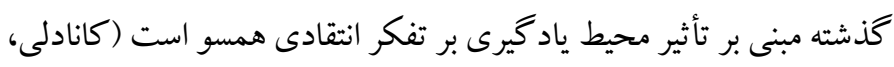

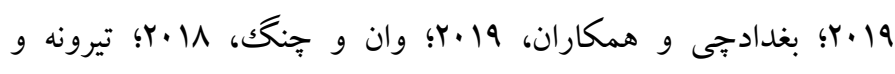

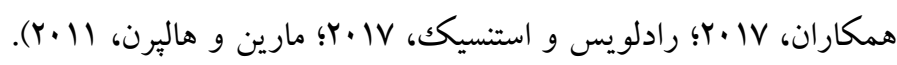

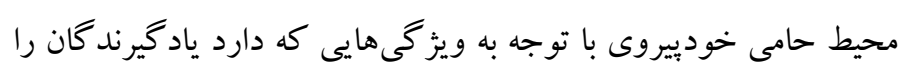

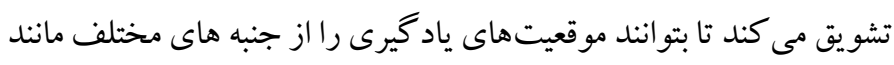

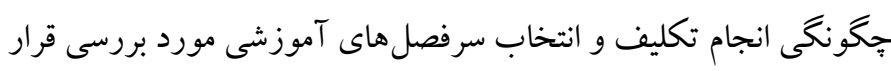

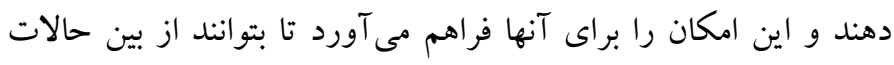

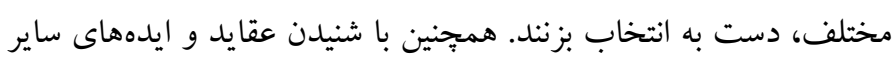
دانش آموزان و بذيرش نقدهاى آنها، فرصتى براى فكر كردن به ديد

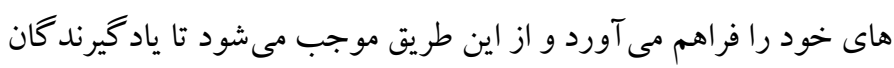
بيشترين درگيرى در فعاليتهاى يادگيرى خود داشته باشند. نظريه

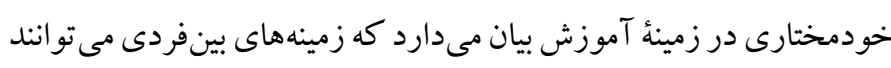

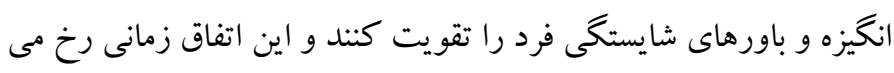

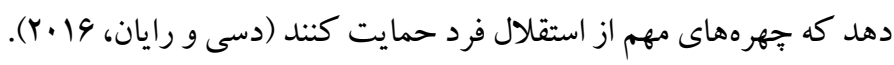

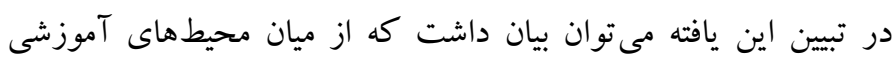

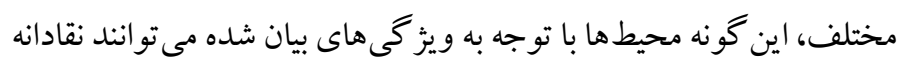

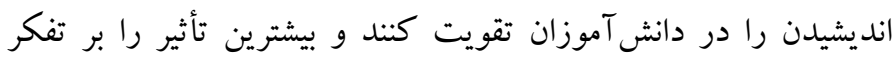


علّى از نتايج بايد احتياط كرد. طرح بثوهش حاضر از نوع همبستخى بود،

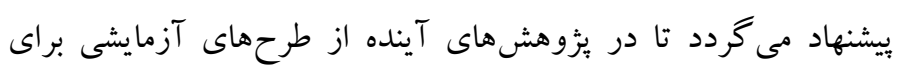

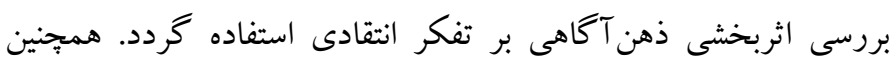

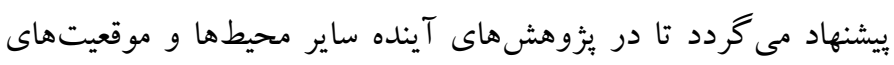

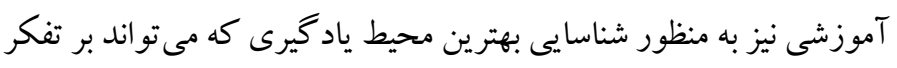

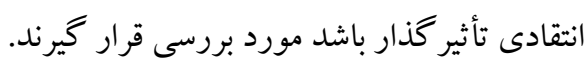

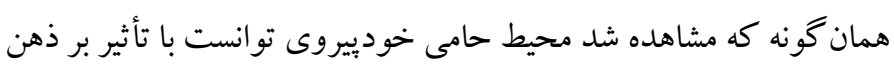

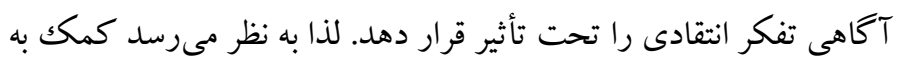

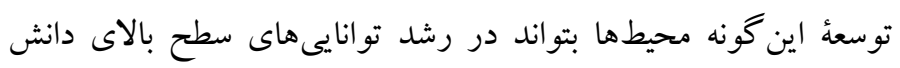

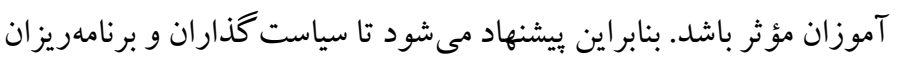

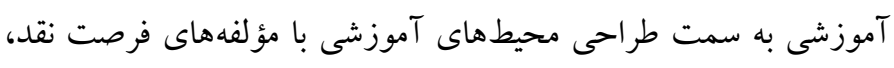

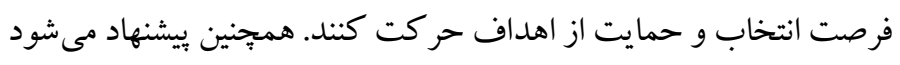

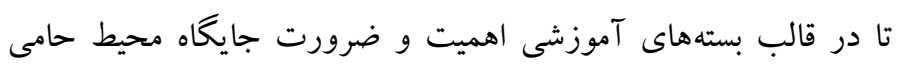

خودييروى براى معلمان و كادر آموزشى اجرايى مدارس تبيين شود. علاوه بر اين از آنجايى كه ذهن آكاهى توانست بين محيط و تفكر انتقادى آن

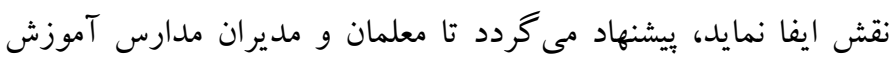
مهارتهاى مر تبط با ذهن آكاهى را در قالب برنامههاى مكمل در كنار ساير آموزش ها براى دانش آموزان در نظر بـيرند.

ملاحضات اخلاقى بيروى از اصول اخلاق ئوهش: اين مقاله بركرفته از ر ساله دكترى نويسنده اول

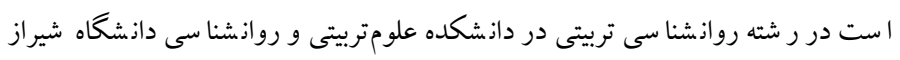

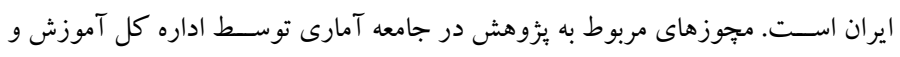
يرورش استان فارس صادر شده است.

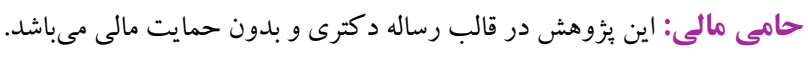

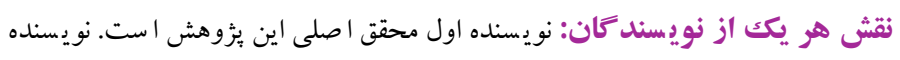

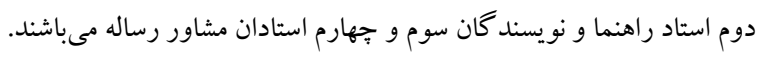

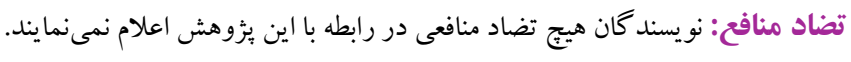

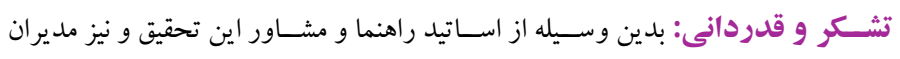

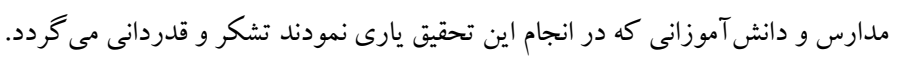

به حالت آرامش است. علاوه براين، هدف از تمرين ذهن آكاهى اين نيست

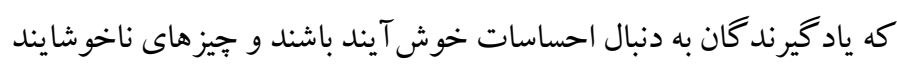
را دور سازند. ذهن آكاهى بايهاى براى مشاهده عميق و درك دئ دلايل و و شرايط لازم براى وقوع يكك بديده خاص است كه در تفكر انتقادى درباره

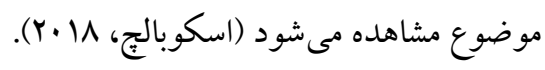
در نهايت نتايج بيانگر اين بود كه ذهن آكاهى توانست بين محيط حامى النى

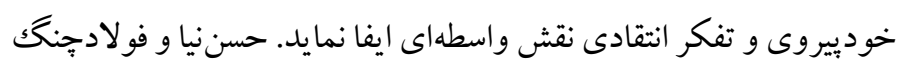

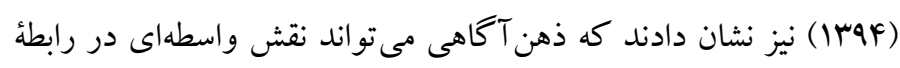
بين محيط ياد گيرى سازنده گرا و فرسود گیى تحصيلى ايفا كند. علاوه براين،

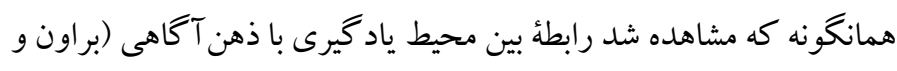

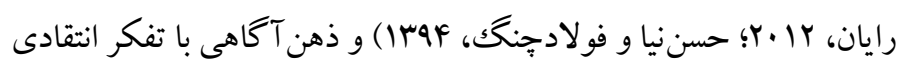

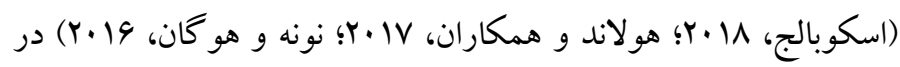

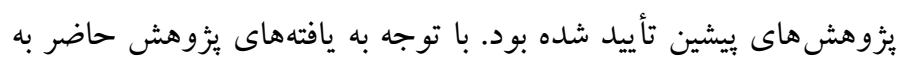

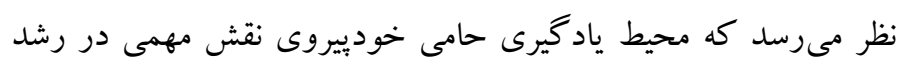

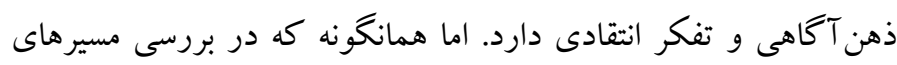

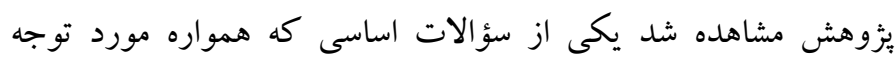

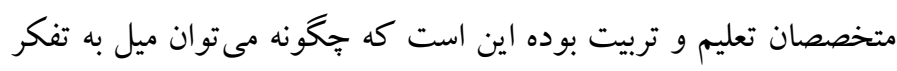

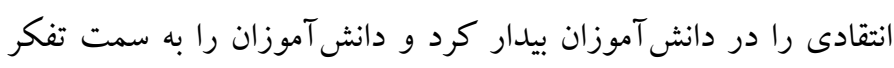
انتقادى راهنمايى كرد. بهنظر مىرسد كه محيط حامى خوديبيروى با مؤلفه

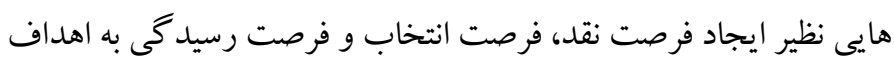

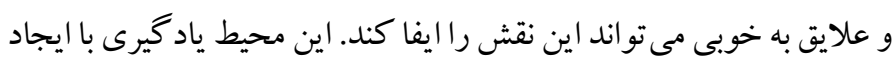

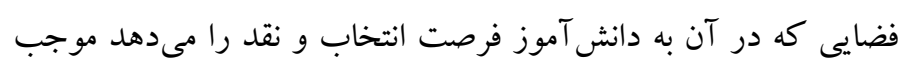

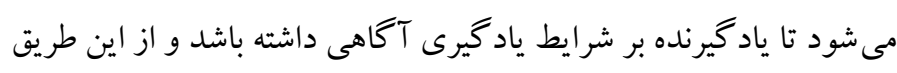
مهارت تفكر انتقادى را برورش دهد.

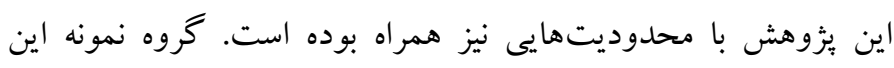

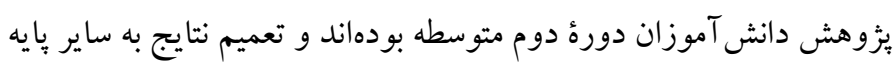

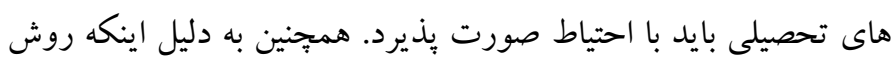

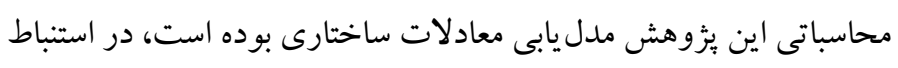




\section{References}

Assor, A. (2012). Allowing choice and nurturing an inner compass: Educational practices supporting students' need for autonomy. In Handbook of research on student engagement (pp. 421-439). Springer, Boston, MA. [Link]

Assor, A., Kaplan, H., \& Roth, G. (2002). Choice is good, but relevance is excellent: Autonomy-enhancing and supporting teacher behaviors predicting students' engagement in schoolwork. British Journal of Educational Psychology. 27, 261-278. [Link]

Baghdadchi, S., Nemerever, Z., and Hadjipieris, P. (2019). Creating environments for critical thinking: building upon multiple choice problems in electrical engineering education. American Society for Engineering Education, Conference Paper. 128-136. [Link]

Brown, K. W., \& Ryan, R. M. (2012). The benefits of being present: mindfulness and its role in psychological well-being. Journal of Personality and Social Psychology. 84(4), 822-848. [Link]

Chen, K. C., \& Jang, S. J. (2010). Motivation in online learning: Testing a model of self-determination theory. Journal of Computers in Human Behavior. 26(4), 741-752. [Link]

Dwyer, C. P., Hogan, M. J., \& Stewart, I. (2014). An integrated critical thinking framework for the 21st century. Think Skills Creat. 12, 43-52. [Link]

Elfatihi, M. (2017). A rationale for the integration of critical thinking skills in EFL/ESL Instruction. Higher Education of Social Science, 12(2), 26-31. [Link]

Facione, P. A. (2013). Critical thinking: What it is and why it counts (2013 Update). San Jose, CA: California Academic Press. [Link]

Ghasemi Jobaneh R, Arab Zadeh M, Jalili Nikoo S, Mohammad Alipoor Z, Mohsenzadeh F. (2015). Survey the Validity and Reliability of the Persian Version of Short Form of Freiburg Mindfulness Inventory. JRUMS. 14 (2):137-150. (Persian). [Link]

Hassannia S, Fouladchang M. (2015). Mindfulness in the relationship between perception of learning environment and academic burnout. Developmental Pschology: Iranian Psychologists. 12, 45, 61-73. (Persian). [Link]

Heidari A, Ghorbani N, Pourhosein R. (2018). The Relationship Between Attachment Style and Life Satisfaction: The Mediating Role of Basic
Psychological Needs Satisfaction. $J$ of psychological science, 70, 17, 643-650. (Persian). [Link]

Holland, A., Dooley, G., \& Fedock, B. (2017). Meditation, Mindfulness, and Critical Thinking: Individual Characteristics in Online Higher Education. Journal of Psychology Cognition. 2(3),170-176. [Link]

Hopthrow, T., Hooper, N., Mahmood, L., Meier, B. P., \& Weger, U. (2016). Mindfulness reduces the correspondence bias. The Quarterly Journal of Experimental Psychology. 70(3), 351 - 360. [Link]

Hoy, W., \& Sweetland, S. (2001). Designing better schools: The meaning and measure of enabling school structures. Educational Administration Quarterly. 37(3), 296-321. [Link]

Kanadli, S. (2019). An investigation of secondary school students' perceived autonomy support, critical thinking tendencies and problem solving skills, Trakya Journal of Education. 9(1), 61-77. [Link]

Marina, L. M., \& Halpern, D. F. (2011). Pedagogy for developing critical thinking in adolescents: Explicit instruction produces greatest gains. Thinking Skills and Creativity. 6, 3-11. [Link]

Mehrinejad A. (2007). Adaptation and Normalization of California Critical Thinking Skills Test. Advances in Cognitive Sciences. 9 (3):63-72. (Persian). [Link]

Mirzaei Fandokht O, Dortaj F, Saadipour E, Ebrahimi Ghavam S, Delavar A. (2020). The relationship between autonomy supportive environmental and academic well-being: the mediating role of basic psychological needs. $J$ of psychological science, 87, 19, 299-311. (Persian). [Link]

Noone, C., \& Hogan, M. J. (2016). A protocol for a randomized active-controlled trial to evaluate the effects of an online mindfulness intervention on executive control, critical thinking and key thinking dispositions in a university student sample. BMC Psychology. 4(1), 1-12. [Link]

Radulovic, A., \& Stancic, M. (2017). What is needed to develop critical thinking in schools? CEPS Journal. 7(3), 9-25. [Link]

Škobalj, E. (2018). Mindfulness and critical thinking: Why should mindfulness be the foundation of the educational process? Universal Journal of Educational Research. 6(6), 1365-1372. [Link]

Tiruneh, D., Cock, M., \& Elen, J. (2017). Designing learning environments for critical thinking: examining effective instructional approaches. 
International Journal of Science and Mathematics Education. 2(12), 2-28. [Link]

Walach, H., Buchheld, N., Buttenmüller, V., \& Kleinknecht, N., \& Schmidt, S. (2006). Measuring mindfulness-The Freiburg mindfulness inventory (FMI). Personality and Individual Differences. 40, 1543-55. [Link]

Wna, Z. H., \& Cheng, M. H. (2018). Classroom learning environment, critical thinking and achievement in an interdisciplinary subject: a study of Hong Kong secondary school graduates. Educational Studies. 18, 1-28. [Link]

zafari S, Khademi Eshkezari M. (2020). The structural model of the role of cognitive emotion regulation strategies, mindfulness and perfectionism in predicting emotional problems in students. $J$ of psychological science, 87, 19, 321-328. (Persian). [Link] 